\title{
THE SUSTAINABLE CONSTRUCTION OF THE OLD COMMUNITY IN BEIJING N0.72 OF TIANQIAO AS AN EXAMPLE
}

\author{
DOI: 10.18485/arh_pt.2020.7.ch5
}

\author{
_ Xue Kang \\ Breuer Marcel Doctoral School, Faculty of Engineering and Information Technology \\ University of Pécs, Boszorkány u. 2, H-7624 Pécs, Hungary, kangxue1017@gmail.com \\ _ Yufang Zhou \\ School of Architecture, China Central Academy of Fine Arts, \\ Huajiadinan Str. 8, Chaoyang, Beijing, China, zhouyufang@cafa.edu.cn \\ _ Gabriella Medvegy \\ Faculty of Engineering and Information Technology University of Pécs, \\ Boszorkány u. 2, H-7624 Pécs, Hungary, medvegygabriella@pmmik.pte.hu
}

\begin{abstract}
Cities are the core space of human life and the comprehensive crystallization of human civilization. The city construction gradually turns to globalization and internationalization, along with the progress of knowledge and the update of technology. As a historic capital, Beijing also faces the same challenges of modernization and urbanization as other international cities. How to make cities more suitable for future life is the goal of contemporary architects and urban planners. The sustainable community construction of Beijing Tianqiao art district, which started in 2017, is an experimental exploration of the future development of old urban communities. No.72 has been transformed from a vacant rental house into a community cultural public service space, one of a series of projects in the Tianqiao arts district. The project attempts to create a relaxed public space in a dense city. Redesigning the abandoned or passively used space in the old community and giving it new functions is an effective way to stimulate the vitality of the community and serve the urban residents in this case. The Tianqiao arts district, as a typical traditional community in Beijing, makes the project more representative. Repair the city from the tiny Spaces of the community, from point to line, and then connect the whole city into a network. The innovation of community micro-governance and the improvement of community self-service capacity are the beginning of the long work to improve urban space.
\end{abstract}

KEYWORDS _ urban renewal, community, sustainable, space governance

\section{INTRODUCTION}

The gathering crowd developed into a "city", and the trading society produced a "urbanization". Renewal is not a strange phenomenon in the process of urban development. The urbanization of a city must have experienced a relatively complete cycle, and repeated exploration in multi-level practice, operation and conflict, and finally chose to maintain the balance between development and cultural tradition, there is a mature city.

At present, the pace of globalization is accelerating, and Beijing is gradually becoming an "international city". However, in the rapid development of urbanization, the appearance of the modern 
city style convergence, the ancient city economic recession, the loss of urban characteristics and vitality and other problems, so that Beijing is facing unprecedented challenges on the road of urban renewal. Especially for the ancient Southern District in the center of Beijing. The Tianqiao area in the south of Beijing has a history of nearly 600 years. As an integral part of the historic context of the ancient Beijing, its development and construction are related to the integrity and diversity of Beijing's cultural development. The unique culture of Beijing hutong shows various disadvantages in the development of urbanization, which brings annoyance and inconvenience to people living in the city, and also has some influence on the operation of the city. Transforming traditional hutongs into livable modern communities is one of the tasks of urban renewal.

\section{METHODOLOGY}

\section{Urban regeneration}

In the context of urban development, the alternation between ancient and modern urban space becomes more and more intense. The functions of the ancient city are failing intermittently, and the current situation such as crowded traffic, high commuting costs, and security risks is in urgent need. And modern city means efficient life style, advanced functional facilities, preferential policies and so on.

The concept of urban renewal was given at the first seminar on urban renewal held in Holland in 1858. In a nutshell, urban renewal is to change the environment through repairs, transformations, and other means to meet the increasing material and cultural needs and spiritual civilization needs of mankind. With the progress of the city, the old houses in the past no longer adapt to the development needs. If the city is to function, it will inevitably be renewed. This is not transferred by the will of the person.

\section{Ecological urbanism}

Ecological Urbanism is a revolution in the modes and methods of urban planning, design, construction and management, and even a revolution in a new way of life. It is also the theoretical pioneer of the concept of Green Infrastructure. Ecological Urbanism inherits the viewpoint of landscape urbanism and constructs the connotation of ecology. The idea of understanding the city as an ecosystem dates back to the Archigram group in London in the 1960s. The theory has been proven to apply to a range of urban development problems, such as the restoration of industrial wasteland, the revival of shrinking urban centers and the development of new cities in the context of rapid development.

\section{Community building}

Community building, also known as community empowerment. "Community" refers to the people who form a "community of life" with each other and are geographically clustered together. "Community building" is the process of creating such a social-psychological connection between people and between people and the places. The concept of community building can be traced back to the "Bedford Stuyvesant Restoration Corporation" in the United States in 1967. Locally, they re-cultivate the community of the area by repairing them, rather than shoveling off the original building. For the past half century, urban renewal in the United States is mainly driven by the bottom-up and spontaneous "community development corporation" (CDC). The focus of community building in cities is to create residents' sense of community, reshape community life, and emphasize "local" and "cultural".

\section{Placemaking}

The concept of Placemaking was born in the development of "Community building" in Taiwan, China. Placemaking is to use a site of transformation, to activate a place. This concept is based on the unprecedented complexity of contemporary social life background, more constructive, transformative, positive social management. Placemaking focuses on constructing and nurturing the relationship between people and the environment in which they are located. Building Shared value, community 
capacity, and cross-sectoral cooperation in local cities through extensive and focused management of local quality is the foundation of resilient cities and vibrant communities. And in this process, the participants may or may not be residents of the community. This is a more open approach to community building and urban renewal.

\section{THE BACKGROUND OF NO.72 IN TIANQIAO COMMUNITY}

Beijing's history of "urban renewal" can be traced back to nearly 30 years ago-Relocate a part of the population within the framework of no major demolition. Through the introduction of municipal renovation, functional completion and modern design, hutong life has been changed. The new version of Beijing's urban master plan, released in 2017 , clearly states that the ancient city will no longer demolish hutongs and courtyards, and promote the protection and organic renewal of historical and cultural neighborhoods, landscape coordination areas and other traditional bungalow areas. "Organic renewal" replaces "Ancient city reconstruction" and becomes the development direction of ancient city.

In 2017, Beijing international design week initiated a renovation project of vacant houses in Tianqiao community. The organizer invited the architects to make in-depth visits to the residents of the Tianqiao community, design a series of public service spaces that activate the community life, and carry out related cultural service activities with the residents. The inclusion of urban renewal as one of the content sections of design week is rare globally, as international design weeks are almost always dominated by industrial design. No. 72 of Zhaozhuizi hutong is the case to be discussed in this paper, as well as one of the old community renewal exploration during the design week.

\section{The location and history of Tianqiao}

The Tianqiao of south Beijing is located in the southern section of the central axis of Beijing. The nearly 600-year-old Tianqiao area was once a cultural and entertainment venue for the people of Beijing. Set of cultural entertainment, food and beverage snacks and business services as a whole, is the proof of many ancient Beijing people's culture. The rise of Tianqiao culture is not only an economic phenomenon but also a cultural phenomenon leading the beginning of the economic and cultural vitality of ordinary people in modern Beijing. The residents and vendors in Tianqiao area are the main participants and promoters of Beijing's leisure and entertainment life, and this unique folk style has influenced the culture of the whole city (Figure 1). A Chinese proverb says, "Man can prosper the land, and land can prosper the people." Scholars studying the history of the Tianqiao area also refer to this phenomenon as "civilian universities".
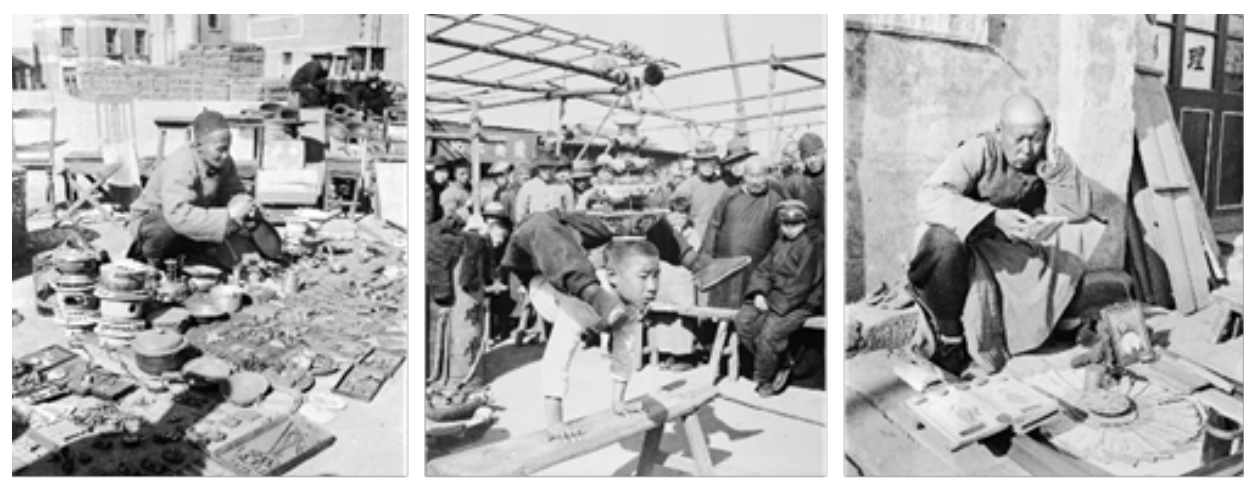

_ Figure 1: left-'Second-hand goods seller at Tianqiao market', https://ma.as/121284/centre-'Young acrobat at Tianqiao market', https://ma.as/121292/right-'Roadside fortune teller', https://ma.as/121304,A Photographer in Old Peking,1933-1946 (by Hedda Morrison) 
Like other fast-growing cities around the world, Beijing suffers from urban disease. In the community of Tianqiao near the center of the capital, the contradiction between modern life style and traditional community space becomes increasingly fierce. In the recent ten years of urban renewal and construction in Beijing, the city has gradually solved a series of problems in the renewal of infrastructure in the ancient hutong life, such as domestic water, garbage treatment, management and construction of public toilets and so on. However, the high-density hutong community space still makes life inconvenient for many residents, so they finally choose to move out of the hutong. This alleviates the high density of community life to some extent, but at the same time produces some empty and wasted building space.

\section{Architectural overview of Zhaozhuizi hutong No. 72}

The no. 72 is located in the middle of Zhaojuezi Hutong in the northern bungalow area of Tianqiao community (Figure 2). According to the measurement, the indoor area of building No. 72 is about 27.5 (Figure 3). From the room layout can be analyzed the original occupants of the building at least two renovations. On one occasion, two entrance halls were illegally constructed on the north side of the building. On another time, the middle partition wall was interrupted and the entrance door on the east side was closed, making the two independent rooms into a set. The additional functional space is a kitchen and bathroom, and there is no toilet in the room. There are no windows on the south side of the building, while the added space on the north side obstructs the internal lighting of the rooms. The indoor lighting is seriously insufficient and the ventilation is poor
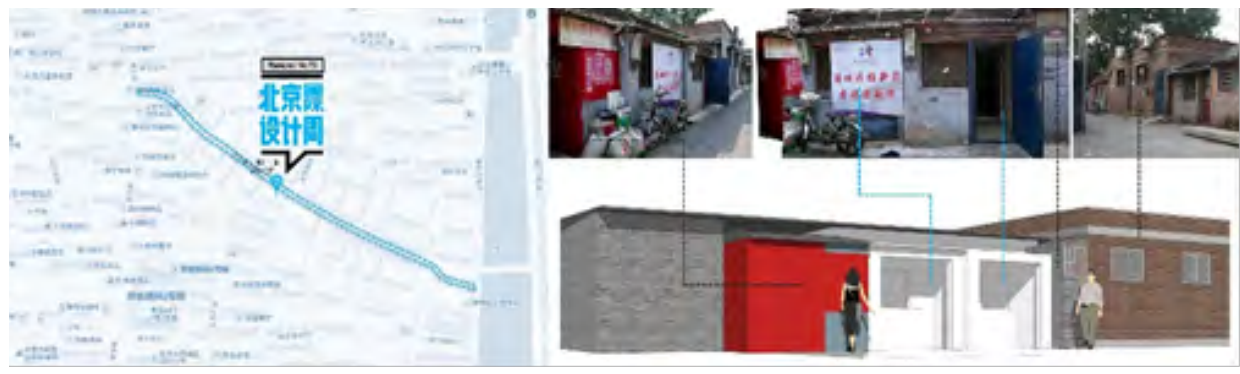

_ Figure 2: left-Location analysis of no. 72 Zhaozhuizi hutong /right-No. 72 facade analysis diagram (by author)
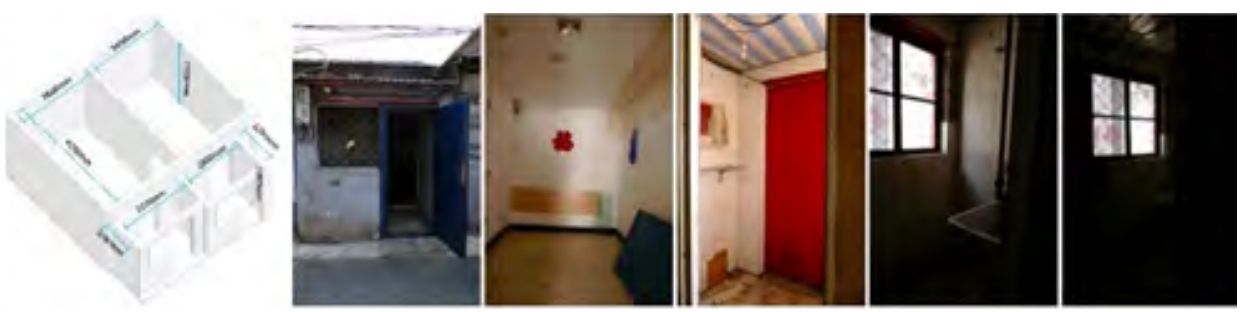

_ Figure 3: left-Spatial scale analysis diagram of No. 72 /right-No. 72 interior photo (by author)

\section{THE RENOVATION STRATEGY OF NO.72 IN TIANQIAO COMMUNITY}

The renovation of no.72 was positioned as a community service module: community medical and health service space. According to the lack of community functions existing in Tianqiao, the purpose of the transformation is to set up a series of community service stations based on the lifestyle and living habits of residents in the community, so as to create a new public space mode for the community. In these new spaces, while providing convenience services, participants will be given new social 
identities, and a more three-dimensional identity interaction network will be established.

\section{Modernization of facilities}

"Repairing the old as old" is the method of cultural relics protection, not the way of urban renewal. Residents are 21 st century people who need modern lifestyles to meet their needs for a better life. Therefore, the building should first meet the convenience of modern people's basic life, such as hot water, electricity safety, sanitation, lighting, ventilation and other basic requirements of healthy life.

\section{Return illegally occupied street space}

In Beijing bungalow construction, there are more illegal addition of the phenomenon. This is closely related to the transition problems in multiple stages of social transformation. It is difficult to fundamentally solve the phenomena left over from history, and mistakes can only be corrected through continuous updates. Returning public space on the street can also solve many problems of the original building.

\section{Suitable for aging design}

China is one of the countries with a rapidly aging population. Beijing's traditional community residents are mostly elderly, who cannot afford expensive relocation costs. Therefore, the age-appropriate design of community public space is particularly important and hidden in every detail of architectural design.

\section{The continuity of community culture}

Modern architectural design should go into hutong, and the concept of design is' new born from the old', emphasizing 'new', but fundamentally old. The essence of community life is the resonance and cohesion of culture, so retaining the original culture of the community is also the basis of design. In particular, there are traditional cultural characteristics of Beijing Tianqiao art culture, Tianqiao performance culture is the core of the community construction.

\section{From community building to Placemaking}

The no. 72 is named the " Community Healthcare Center " $(\mathrm{CHC})$. The moral is to bring a space for healthy living services and medical assistance to community residents. It also represents a desire to energize the community. The architects wanted to use the "design" to guide the "lifestyle", with the community residents jointly managing and using the public service space. Then realize the "management" to "construction" transformation, and constantly in the use of the building to correct the "design." It is also a metaphor for the community as a sub-ecosystem within the urban ecosystem. Guide the community's self-renewal and emphasize self-government of residents.

\section{RECONSTRUCTION PROCESS OF NO.72 IN TIANQIAO COMMUNITY}

Project no. 72 lasted for two and a half months from site exploration, scheme design, construction to participation in the design week exhibition. In the design stage of the scheme due to time, cost and other problems, after several amendments.

The first version of the scheme wants to start from the multi-function and openness of the space (Figure 4). By using the combination of gray mirror + double-sided shelving + reflector, the three parts can be separated or combined separately along the two-way sliding track. Such homogenization units can achieve the transformation of location attributes according to specific spatial functional requirements. The illegal addition of the building has not been removed, and the architects want to install two doors to enter the building through artistic means.

In the second discussion, two design schemes are proposed (Figure 5). The two design intentions put forward in plan 2 are also intended to enrich the applicability of space by resetting and superimposing space functions. Different from Plan 1, which wastes part of the building space, Plan 2 is 
more practical and reasonable.
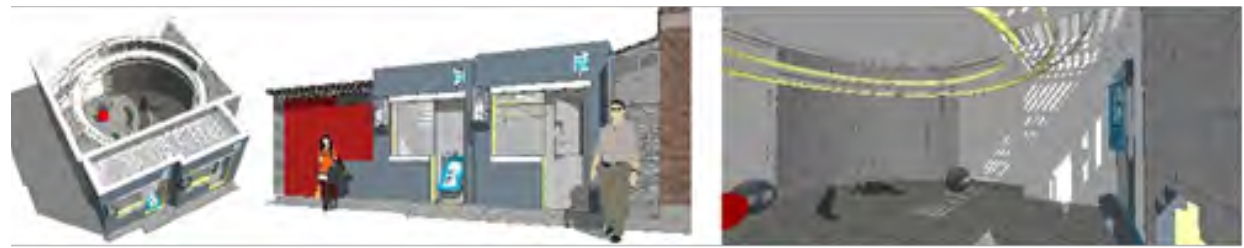

_ Figure 4: The first version of the plan's aerial view, elevation, indoor renderings (by author)
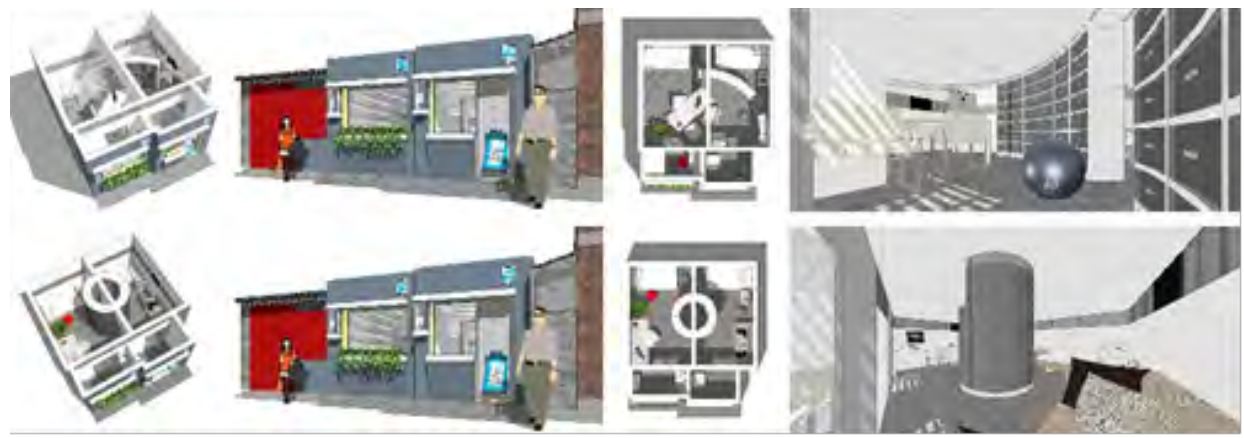

_ Figure 5: Plan 2-1 and 2-2's aerial view, elevation, floor plan, indoor renderings (by author)

The third version of the scheme is based on a development in the second version. The biggest change is the landscape renovation after the demolition of illegal construction (Figure 6). The fourth and fifth versions of the scheme are also about the possibility of illegal addition construction transformation into semi-closed courtyards (Figure 7).
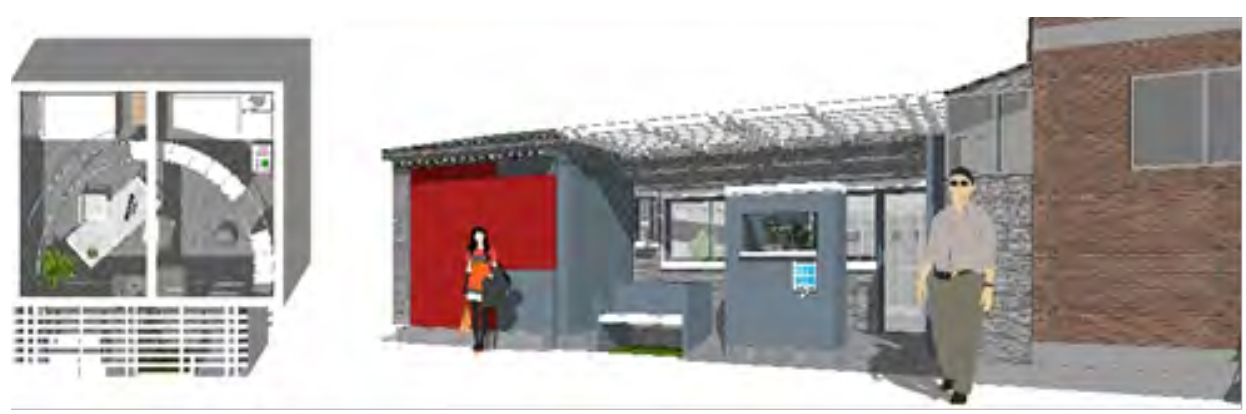

_ Figure 6: The third version of the plan's floor plan, elevation (by author)
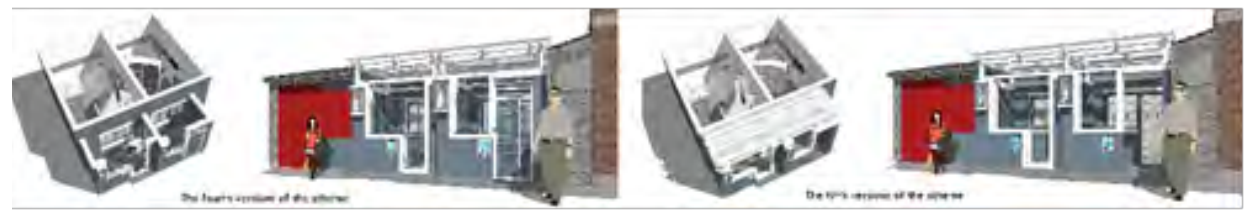

_ Figure 7: The fourth and fifth version of the plan's aerial view, elevation (by author) 
The plan 6 is also the final version (Figure 8). The biggest change lies in the determination of the color of the building's facade, which also determines the identity color named "Community Healthcare Center". Giving architectural identity and personality is an effective way to emphasize the existence of its function.
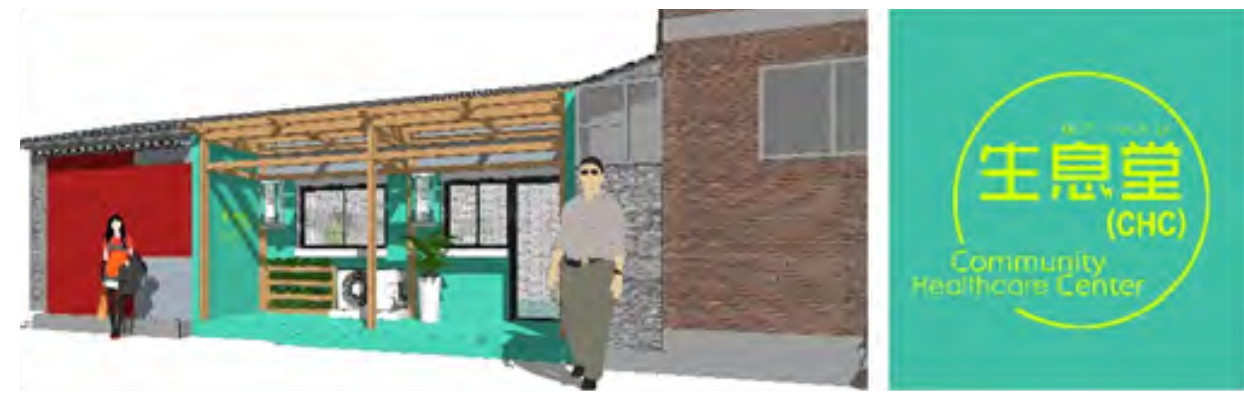

_ Figure 8: The final plan's elevation and Logo (by author)

After the final design scheme is determined, the inner area is 22.12. Illegal additions will be demolished and the enclosed space will be opened. Install 1.5 HP air-conditioned outdoor unit. All around metope is decorated with light steel keel gypsum board, middle enchase gray mirror. The interior of the central partition door hole widened, with arc mobile combination furniture and drapes as partition, dividing into three functional Spaces: consulting room/lounge/ inquiry room.

\section{CONCLUSIONS}

With the acceleration of economic globalization, the advent of mass consumption society and the rapid process of urbanization, social life has become unprecedentedly complex, which objectively requires more constructive, transformative and active social management to integrate the order of social life. There are discordant conflicts between old communities and urban construction, both in physical environment space and function or in living mode and surrounding environment. Such conflicts are becoming more and more prominent with the improvement of urban residents' living needs.

Community is the basic unit of people's life. In the context of urban renewal, community building should be based on local conditions and step by step. The micro-intervention of community space should be emphasized. Firstly, modern and convenient services should be provided, and then community residents should be guided to participate in and manage. Finally, community construction should be developed with community residents as the main body. The objective of project no. 72 is to explore the possibility of creating subscale social services for multiple users in the limited space of traditional hutong.

This project can be said to be a construction experiment, hoping that it will inherit the intimate space of the hutong and revive its social performance, but it is completely new in form. Life in hutongs has remained unchanged for decades, and if such "radical" design allows residents to see the possibilities and diversity of modern life, it could become a progressive practice.

\section{REFERENCES}

_ M Mostafavi, G Dohert, and Harvard University Graduate School of Design. 2016. Ecological Urbanism, Revised Edition. Zürich: Lars Muller. 
_ Simon Sadler. 2005. Archigram: Architecture Without Architecture. Cambridge: The MIT Press.

_ Beijing International Culture Association, and Beijing Xuanwu district "Tianqiao of old Beijing" album editor's committee. 1990. Tianqiao of old Beijing. Beijing: Beijing Publishing Group.

_ Hedda Morrison. 1985. A Photographer in Old Peking. Hong Kong: Oxford University Press.

_ PC Xiang, YM Wang, Q Deng. 2017. "RESEARCH ON URBAN RENEWAL FROM THE PERSPECTIVE OF NATURAL DISASTER VULNERABILITY." In WIT Transactions on Ecology and The Environment, Vol 226, edited by C.A. Brebbia, J. Longhurst, E. Marco, C. Booth,85-94. Southampton: WIT Press.

_ JM Huang. 2017. "Emerging Challenges of Community Empowerment: Exploring a Harmonious Living among Different Community Stakeholders." Landscape Architecture Frontiers, 5(6):56-61.

_ John Friedmann.2010. "Place and Place-Making in Cities: A Global Perspective." Planning Theory \& Practice, 11(2):149-165.

_ SR Wang. 2012. "Evolution of Beijing Tianqiao and Significance of Landscape Construction." Beijing Planning Review, no. 5: 150-153.

- Sady Sullivan. 2009. "Coming Up in Bed Stuy." Brooklyn Historical Society-Blog, July 29. Accessed February 19, 2020. https://www.brooklynhistory.org/blog/bedford-stuyvesant-restoration/. 